02

\title{
Разгорание и затухание импульсной катодолюминесценции в монокристаллах и керамиках $\mathrm{Nd:ИАГ}$
}

\author{
(C) В.И. Соломонов ${ }^{1,2}$, А.В. Спирина ${ }^{19}$, А.С. Макарова ${ }^{1}$ \\ ${ }^{1}$ Федеральное государственное бюджетное учреждение науки Институт электрофизики \\ Уральского отделения РАН, \\ 620016 Екатеринбург, Россия \\ ${ }^{2}$ Уральский федеральный университет имени первого Президента России Б.Н. Ельцина, \\ 620002 Екатеринбург, Россия \\ ฯ e-mail: rasuleva@iep.uran.ru \\ Поступила в редакцию 03.12.2020 г. \\ В окончательной редакции 26.12.2020 г. \\ Принята к публикации 09.02.2021 г.
}

Исследовалась кинетика импульсной катодолюминесценции ионов $\mathrm{Nd}^{3+}$ в монокристаллах и керамических образцах $\mathrm{Nd}: И А Г$ После прекращения воздействия электронного пучка длительностью $2 \mathrm{~ns}$ в этих веществах возникает люминесценция. Оптические переходы наблюдаются с уровня ${ }^{2} F_{5 / 2}$ и проявляются в ультрафиолетовой и видимой областях спектра, а с уровня ${ }^{4} F_{3 / 2}-$ в ближней инфракрасной области. Кинетика люминесценции характеризуется разгоранием и затуханием и описывается разностью двух экспоненциальных функций. Определено, что характерные времена затухания люминесценции являются временами жизни излучательных уровней ${ }^{2} F_{5 / 2}$ и ${ }^{4} F_{3 / 2}$, а время разгорания определяется механизмом их подкачки. Причем подкачка самой верхней штарковской компоненты уровня ${ }^{2} F_{5 / 2}$ осуществляется в процессе линейной рекомбинации ионизованного иона неодима со свободными электронами, а уровня ${ }^{4} F_{3 / 2}-$ за счет безызлучательных переходов с верхних уровней.

Ключевые слова: катодолюминесценция, разгорание, затухание, кинетика, Nd:ИАГ.

DOI: $10.21883 /$ OS.2021.07.51076.295-20

\section{Введение}

Ион $\mathrm{Nd}^{3+}$ используется в качестве иона-активатора в монокристаллах и керамиках $\mathrm{Y}_{3} \mathrm{Al}_{5} \mathrm{O}_{12}$ (Nd:ИАГ) для создания высокоэффективных и мощных лазеров. Эти лазеры являются одними из самых распространенных и широко используемых на практике [1-4]. Сам материал

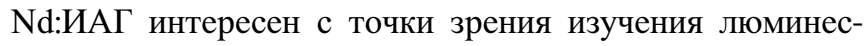
ценции, так как $\mathrm{Nd}^{3+}$ в его кристаллической матрице может иметь две электронные конфигурации $4 f^{3}$ и $4 f^{2} 5 d^{1}$, электроны которых активны в люминесценции [5-7].

Существует много работ, посвященных изучению люминесценции ионов $\mathrm{Nd}^{3+}$ в кристаллической матрице $\mathrm{Y}_{3} \mathrm{Al}_{5} \mathrm{O}_{12}$, которые включают идентификацию полос излучения, поведение их интенсивности в зависимости от концентрации примеси, а также изменение интенсивности люминесценции во времени после воздействия возбуждающего излучения. Причем при исследовании кинетики в подавляющем большинстве работ изучается только стадия затухания люминесценции, в то время как процесс разгорания остается неизученным [5-10].

В настоящей работе приводятся результаты исследования импульсной катодолюминесценции (ИКЛ) ионов неодима в моно- и поликристаллических образцах $\mathrm{Nd}^{3+}: \mathrm{Y}_{3} \mathrm{Al}_{5} \mathrm{O}_{12}$ с целью определения специфики кинетики полос люминесценции, включающей процессы разгорания и затухания, в широком оптическом диапазоне.

\section{Образцы и экспериментальная аппаратура}

В качестве объектов исследования использовались лазерные монокристаллы со средним содержанием неодима 0.85 at.\%, выращенные в ФГУП НИИ „Полюс“ (г. Москва) методом горизонтально направленной кри-

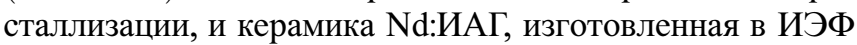
УрО РАН по методике, описанной в [4], при этом содержание неодима в них составило около 1 at.\%.

Кинетика ИКЛ изучалась с помощью экспериментальной установки, блок-схема которой приведена на рис. 1.

Источником возбуждения ИКЛ служит наносекундный ускоритель электронов типа РАДАН-303 $(1,2)$. Его высоковольтный блок (1) формирует импульсы напряжения амплитудой $130-200 \mathrm{kV}$ и длительностью $2 \mathrm{~ns}$. Это напряжение прикладывается к вакуумному диоду (2), в качестве которого используется промышленная электронная трубка ИМА3-150Э. Электронный пучок из диода выводится в металлическую камеру (3), где образцы устанавливаются на аппаратный столик (4). Поток люминесценции от образца из камеры выводится посредством многожильного световода (5) через коллиматор (6) в монохроматор МДР-41 (7). В качестве приемников оптического излучения использовались два вида регистраторов - ФЭУ-62 и ФЭУ100 (8), питание которых обеспечивается блоком (9). Сигнал с ФЭУ регистрируется осциллографом Кeysight 


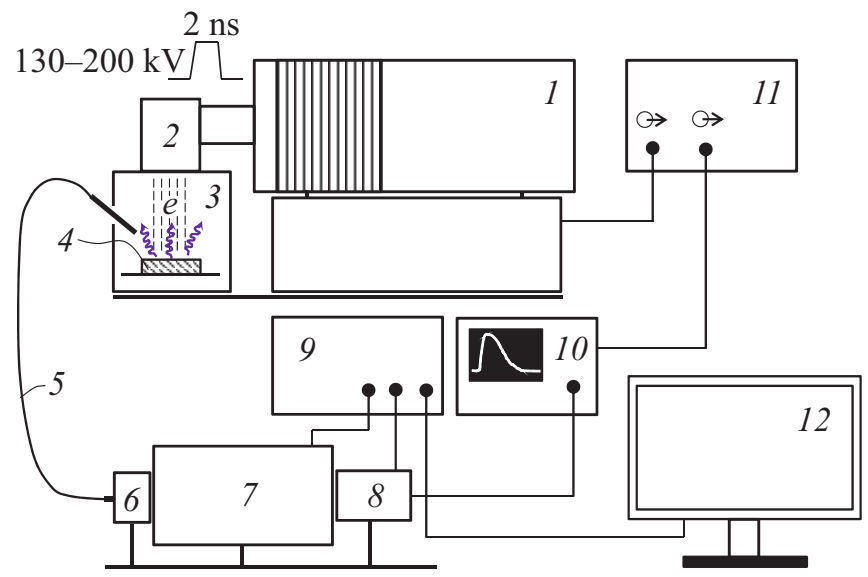

Рис. 1. Блок-схема экспериментальной установки: 1 - генератор высоковольтных наносекундных импульсов напряжения РАДАН-303, 2 - источник электронного пучка, 3 - экранированная камера, 4 - образец, 5 - волоконный световод, 6 - коллиматор для световода и блок светофильтров, 7 монохроматор, $8-\Phi Э У, ~ 9-$ блок управления и регистрации, 10 - осциллограф, 11 - генератор тактовых импульсов, $12-$ ПК.

DSOX2014A (10). С помощью генератора Г5-63 (11) обеспечивается включение ускорителя и запуск осциллографа с задаваемой временной задержкой. Варьирование напряжения питания для ФЭУ на блоке (9) осуществляется через компьютер (12). ИКЛ возбуждалась пучком электронов со средней энергией $E_{e}=150 \mathrm{keV}$ при плотности тока $j_{e}=100 \mathrm{~A} / \mathrm{cm}^{2}$ длительностью $t_{e}=2 \mathrm{~ns}$. Измерения проводились в воздухе при комнатной температуре образцов. Обзорный спектр люминесценции в диапазоне 200-1200 nm регистрировался на этой же аппаратуре. Погрешность измерения длины волны составила $0.5 \mathrm{~nm}$.

\section{Результаты и их обсуждение}

Спектры люминесценции монокристаллов и керамики $\mathrm{Nd}^{3+}:$ ИАГ имеют одинаковую структуру четко разрешаемых полос (рис. 2). В ультрафиолетовом (УФ) и видимом диапазонах спектра наблюдаются полосы оптических переходов с высокоэнергетического уровня ${ }^{2} F_{5 / 2}$ электронной конфигурацией $4 f^{2} 5 d^{1}$, расщепленного на три штарковские компоненты $\left(v_{0}=37775 \mathrm{~cm}^{-1}\right.$, $v_{1}=37864 \mathrm{~cm}^{-1}, v_{2}=38153 \mathrm{~cm}^{-1}$ ) [5-7], на уровни $4 f^{3}$ конфигурации иона неодима. В инфракрасной (ИК) области наблюдается внутрицентровая $f-f$-люминесценция иона неодима на переходах с верхнего уровня ${ }^{4} F_{3 / 2}$ на нижние уровни ${ }^{4} I_{9 / 2},{ }^{4} I_{11 / 2}[11]$.

Важнейшая информация о центрах свечения заложена в кинетике люминесценции. В случае ИКЛ мы имеем дело с „мгновенным“ импульсом возбуждения, во время действия которого люминесценция не успевает развиться. Она возникает после внешнего воздействия.
Характерные кривые кинетики полос для трех областей спектра приведены на рис. 3. Заметим, что качественная картина кинетики для керамик и монокристаллов не отличается. Видно, что в кинетике всех полос неодима характерно наличие максимума. Причем время достижения максимума у полос УФ (кривая 1) и видимой (кривая 2) областей близко и составляет 21 и $27 \mu \mathrm{s}$ соответственно, в то время как у полос ИК области (кривая 3) оно на порядок больше и составляет в среднем около $200 \mu \mathrm{s}$. Для определенности назовем временное поведение интенсивностей до достижения максимума разгоранием, а после максимума - затуханием люминесценции.

Для каждой полосы люминесценции, соответствующей оптическому переходу с уровня $i$ на уровень $k$, кинетическая кривая $I_{i k}(t)$ описывается линией регрессии с коэффициентом $r^{2}=0.99$ (на рис. 3 сплошные линии), представляющей собой разность двух экспоненциальных

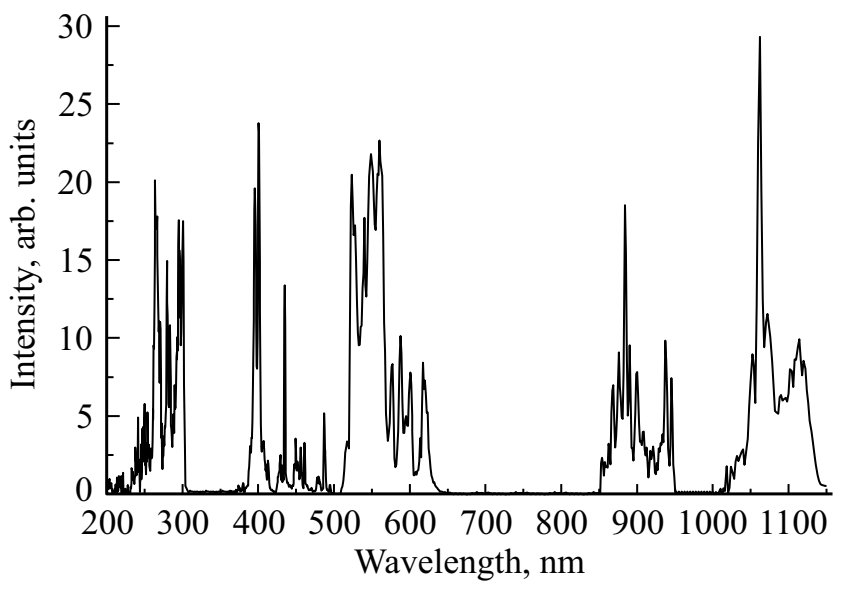

Рис. 2. Спектр ИКЛ монокристалла Nd:ИАГ.

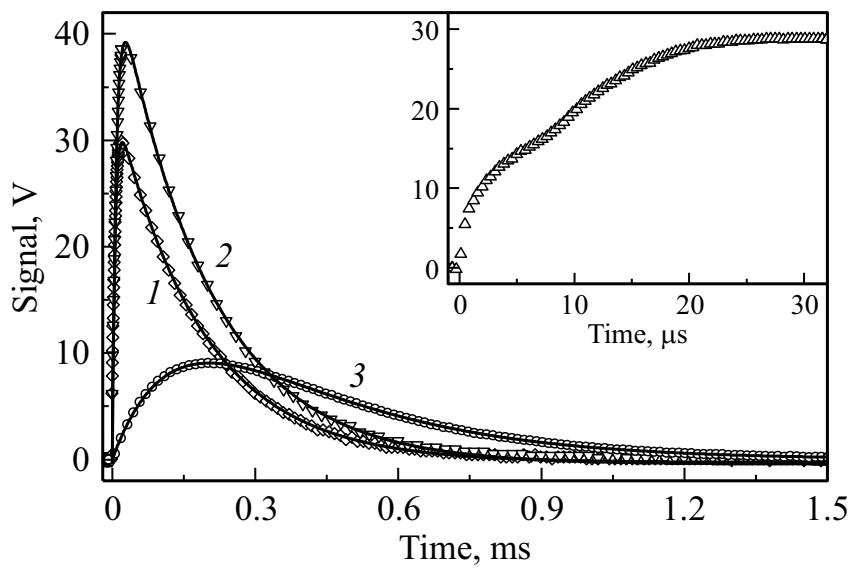

Рис. 3. Характерная кинетика люминесценции спектральных полос в различных областях спектра: $1-$ УФ $(\lambda=321 \mathrm{~nm})$, $2-$ видимый диапазон $(\lambda=461 \mathrm{~nm}), 3-$ ИК $(\lambda=1052 \mathrm{~nm})$. На вставке приведен характерный участок разгорания полосы видимого диапазона при $\lambda=396 \mathrm{~nm}$. 
функций:

$$
I_{i k}(t)=I_{0 i k}\left[\exp \left(-\frac{t}{\tau_{2}}\right)-\exp \left(-\frac{t}{\tau_{1}}\right)\right] .
$$

В этой формуле $I_{0 i k}(t)-$ интенсивность в максимуме, $t$ - текущее время, $\tau_{1}<\tau_{2}-$ постоянные времени, характеризующие процессы разгорания $\left(\tau_{1}\right)$ и затухания $\left(\tau_{2}\right)$ люминесценции.

По кинетическим параметрам $\tau_{1}$ и $\tau_{2}$ все наблюдаемые спектральные полосы всех образцов четко разделяются на 4 группы. Практически все полосы, лежащие в УФ и видимой областях (за исключением нескольких линий, о которых речь пойдет ниже), мы отнесли к первой группе. Для них характерное время разгорания составляет $\tau_{1}=4.5 \pm 0.2 \mu$ для монокристаллов и керамики, а время затухания $-\tau_{2}=175 \pm 2 \mu$ s для монокристаллов и $190 \pm 3 \mu$ s для керамики. Во второй группе полос при $\lambda=435,525,549,556.5,560.5 \mathrm{~nm}$ время разгорания становится чуть больше и равным $\tau_{1}=7.0 \pm 0.2 \mu$ для всех образцов, а время затухания составляет $\tau_{2}=180 \pm 3 \mu \mathrm{s}$ для монокристаллов и $192 \pm 3 \mu$ s для керамики. Для этой группы полос на кривых разгорания проявляется небольшой перегиб, аналогичный тому, который показан на вставке рис. 3. Для третьей группы полос при $\lambda=396$ и $400.5 \mathrm{~nm} \tau_{1}=12.0 \pm 0.9 \mu$ s для монокристаллов и керамики, а $\tau_{2}=195 \pm 4 \mu$ s для монокристаллов и $210 \pm 2 \mu \mathrm{s}$ для керамики. И, наконец, для четвертой группы полос, соответствующих переходам ${ }^{4} F_{3 / 2} \rightarrow{ }^{4} I_{9 / 2},{ }^{4} I_{11 / 2}$ в ИК области, процесс разгорания характеризуется временем $\tau_{1}=135.0 \pm 5 \mu \mathrm{s}$ для монокристаллов и $95 \pm 3 \mu \mathrm{s}$ для керамики, а время затухания для монокристаллов и керамики одинаково и равно $\tau_{2}=290 \pm 2 \mu \mathrm{s}$. Приведенные отклонения в значениях характерных времен являются статистическим разбросом соответствующих величин в соответствующих группах спектральных полос.

Излучательными уровнями первых трех групп спектральных полос являются три штарковские компоненты уровня ${ }^{2} F_{5 / 2}$ иона неодима с электронной конфигурацией $4 f^{2} 5 d^{1}$ (рис. $4, a$ ), а для четвертой группы уровень ${ }^{4} F_{3 / 2}$ иона $\mathrm{Nd}^{3+}$ с электронной конфигурацией $4 f^{3}$, имеющий две штарковские компоненты (рис. $4, b$ ). Заметим, что на него нет излучательных переходов с уровня ${ }^{2} F_{5 / 2}$.

Для выяснения физической природы разгорания и затухания люминесценции рассмотрим процессы, способные привести к наблюдаемому временному поведению интенсивностей полос. Исходим из того, что интенсивность люминесценции на любой спектральной полосе при $\lambda_{i k}$ пропорциональна заселенности излучательного уровня $C_{i}$, поэтому ее временное поведение должно повторять кинетику заселенности излучательного уровня. После выключения электронного пучка заселенность излучательного уровня определяется кинетическим уравнением

$$
\frac{d C_{i}}{d t}=f(t)-\frac{C_{i}}{\tau_{i}}
$$

где $\tau_{i}-$ эффективное время жизни излучательного уровня, $f(t)$ - функция, учитывающая процессы подкачки этого уровня в процессах релаксации созданных в образце электронами пучка электронно-дырочных пар с концентрацией неравновесных носителей зарядов (электронов и дырок) $n_{e 0}$.

После отключения возбуждения концентрация неравновесных носителей заряда спадает в соответствии с кинетическим уравнением

$$
\frac{d n_{e}}{d t}=-B n_{e}^{2}-A n_{e},
$$

где $B$ - константа скорости реакции образования свободных и автолокализованных экситонов, $A=k N^{+}-$ вероятность захвата свободного электрона локализованными дырками, концентрация которых равна $N^{+}, k-$ константа скорости этого захвата, имеющая величину порядка $10^{-10} \mathrm{~cm}^{3} / \mathrm{s}$ при линейной рекомбинации. В этом случае функция подкачки для самых высоких излучательных уровней принимает вид

$$
f(t)=\beta_{i} B n_{e}^{2}+\alpha_{I} A n_{e},
$$

где $\beta_{i}$ и $\alpha_{i}-$ коэффициенты ветвления, которые определяют долю процессов рекомбинации, приводящих к возбуждению именно $i$-го излучательного уровня центра люминесценции.

Чтобы решение уравнения (2) имело вид экспериментально наблюдаемой зависимости (1), функция накачки $f(t)$ должна иметь экспоненциальный вид. Такая ситуация возникает при относительно больших $t \geq t_{e}+A^{-1}$ [12], когда доминирующим механизмом подкачки является линейная рекомбинация электроннодырочных пар, в которой захват свободного электрона $e$ осуществляется ионизованным центром люминесценции $C^{+}$, при этом образуется возбужденный на $i$-й уровень центр люминесценции $C_{i}$ с выделением избыточной энергии $\Delta E$, например, в виде фононов:

$$
e+C^{+} \rightarrow C_{i}+\Delta E .
$$

Тогда в формулах (3) и (4) можно пренебречь первым слагаемым в правой части и, определив из (3) явное выражение для $f(t)$, получаем кинетическое уравнение для заселенности излучательного уровня $C_{i}$ :

$$
\frac{d C_{i}}{d t}=\alpha_{i} \frac{n_{e 0}}{\tau_{r}} \exp \left(-\frac{t}{\tau_{r}}\right)-\frac{C_{i}}{\tau_{i}} .
$$

Здесь $\tau_{r}=A^{-1}=\left(k C^{+}\right)^{-1}-$ характерное время линейной рекомбинации в реакции $(5)$,

$$
n_{e 0} \approx \frac{E_{e} j_{e} t_{e}}{3 E_{g} e d_{e}} \approx 10^{18} \mathrm{~cm}^{-3}
$$

- созданная электронами пучка с параметрами $E_{e}, j_{e}$ и $t_{e}$ концентрация электронно-дырочных пар в ИАГ, $e-$ элементарный заряд, $E_{g} \approx 7.95 \mathrm{eV}$ - ширина запрещенной зоны [13], $d_{e} \approx 100 \mu \mathrm{m}-$ глубина проникновения 
$a$

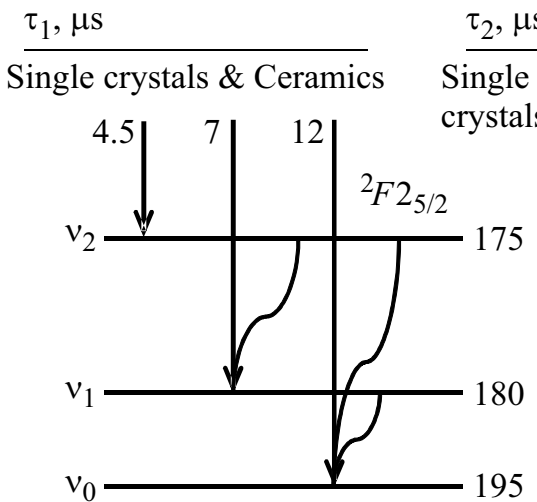

$\frac{\tau_{1}, \mu \mathrm{s}}{135-\text { Single crystals }} \underset{\begin{array}{c}\tau_{2}, \mu \mathrm{s} \\ 95-\text { Ceramics }\end{array}}{\begin{array}{l}\text { Single crystals } \\ \text { \& Ceramics }\end{array}}$

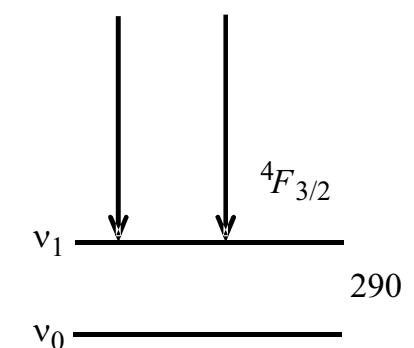

Рис. 4. Штарковские компоненты излучательных уровней ${ }^{2} F_{5 / 2}(a)$ и ${ }^{4} F_{3 / 2}(b)$ иона неодима. Прямые стрелки - подкачка подуровней, волнистые стрелки - безызлучательные переходы; $\tau_{1}, \tau_{2}$ - характерные времена соответственно разгорания люминесценции и жизни соответствующих излучательных подуровней.

электронов пучка в ИАГ, которая была оценена по выражению, приведенному в [14]. Решение этого уравнения при начальном условии $C_{i}(t=0)=0$, которое реализуется при выключении электронного пучка малой длительности, принимает вид

$$
C_{i}(t)=\alpha_{i} \frac{n_{e 0} \tau_{i}}{\tau_{i}-\tau_{r}}\left[\exp \left(-\frac{t}{\tau_{i}}\right)-\exp \left(-\frac{t}{\tau_{r}}\right)\right] .
$$

Полученная теоретическая зависимость качественно совпадает с экспериментальной кривой (1). Однако из формулы (7) нельзя однозначно сказать: какое из характерных времен $\tau_{1}$ или $\tau_{2}$ в экспериментальной зависимости (1) является временем жизни излучательного уровня, так как в (7) $\tau_{i}$ может быть как больше, так и меньше $\tau_{r}$. Для однозначной идентификации характерных времен проведем дополнительный анализ.

Логично предположить, что реакция (5) наиболее эффективна для самого высокого излучательного уровня ${ }^{2} F_{5 / 2}$ из-за наиболее низкого дефекта энергии $\Delta E$. Причем в наиболее „чистом“ виде она проявляется для самой верхней штарковской компоненты $v_{2}$ этого уровня, поскольку для него нет дополнительных источников подкачки. Для этой компоненты измеренное время разгорания $\tau_{1}=\tau_{r}=\left(k C^{+}\right)^{-1}=4.5 \mu \mathrm{s}$. Это означает, что концентрация ионизованных электронным пучком центров люминесценции составляет величину порядка $10^{16} \mathrm{~cm}^{-3}$, т.е. около $1 \%$ от концентрации электронно-дырочных пар. На две других штарковских компоненты $\left(v_{1}\right.$ и $\left.v_{0}\right)$ этого уровня осуществляется дополнительная подкачка за счет безызлучательных переходов с верхних компонентов в результате электронфононных взаимодействий (рис. 4, волнистые линии). Эти источники приводят к увеличению времен разгорания спектральных полос, для которых излучательными уровнями являются нижние компоненты уровня ${ }^{2} F_{5 / 2}$. Поэтому можно считать, что для всех полос УФ и видимого диапазонов длин волн измеренное время разгорания является временем накачки излучательного уровня.
Тогда время затухания люминесценции, одинаковое для всех спектральных полос, начинающихся с одного и того же излучательного уровня, является временем жизни этого уровня, а не временем оптического перехода. Причем для керамических образцов это время жизни чуть больше, чем для монокристаллов. Причины этого отличия пока не выяснены.

Для всех спектральных полос ИК области, начинающихся с излучательного уровня ${ }^{4} F_{3 / 2}$ иона $\mathrm{Nd}^{3+}$, время затухания $\tau_{2}$ составляет величину $290 \mu \mathrm{s}$ (рис. 4,b) в керамических и монокристаллических образцах. Эта величина не сильно отличается от времени жизни уровня ${ }^{4} F_{3 / 2}$, измеренного при фотовозбуждении $[9,10]$. Время разгорания этих полос на порядок больше, чем у полос с излучательным уровнем ${ }^{2} F_{5 / 2}$. Это связано с тем, что основным механизмом подкачки уровня ${ }^{4} F_{3 / 2}$ являются безызлучательные переходы с верхних уровней, времена жизни которых значительно больше времени релаксации электронно-дырочных пар, и в спектре отсутствуют полосы оптических переходов ${ }^{2} F_{5 / 2} \rightarrow{ }^{4} F_{3 / 2}$. Сильное различие времени разгорания $\tau_{1}$ для монокристаллов $(135 \mu \mathrm{s})$ и керамических образцов $(95 \mu \mathrm{s})$ может быть обусловлено, во-первых, наличием введенной в процессе производства керамики дополнительной примеси, которая может появиться как на начальной стадии приготовления при использовании шаров для помола нанопорошков, так и на этапе прессования с применением спекающих и пластифицирующих добавок [4]. В этом случае возникающая дефект-ловушка может перехватывать на себя часть потока подкачки уровня ${ }^{4} F_{3 / 2}$. Во-вторых, различие времен разгорания в монокристалических и керамических образцах может зависеть от концентрации неодима в них. В наших экспериментах мы лишь увидели, что интенсивность полос люминесценции в ИК области ослабевает в керамиках по сравнению с монокристаллами. Возможно, что есть и другие причины, которые в комплексе с вышеперечисленными или по отдельности приводят к различию 
времен разгорания люминесценции, но в любом случае, это требует дополнительных исследований.

\section{Выводы}

В системе энергетических уровней неодима в ИАГ имеются пять излучательных уровней: три штарковские компоненты уровня ${ }^{2} F_{5 / 2}$ и две штарковские компоненты уровня ${ }^{4} F_{3 / 2}$. Оптические переходы с уровня ${ }^{2} F_{5 / 2}$ проявляются в УФ и видимой областях спектра, а с уровня ${ }^{4} F_{3 / 2}$ - в ближней ИК области.

Кинетика ИКЛ всех полос неодима в иттрийалюминиевом гранате характеризуется разгоранием и затуханием, описываемых разностью двух экспоненциальных функций. Характерное время затухания люминесценции является временем жизни излучательного уровня, а время разгорания определяется механизмом подкачки излучательного уровня в процессе рекомбинации электронно-дырочных пар, создаваемых в веществе электронами возбуждающего пучка. Причем подкачка верхней штарковской компоненты уровня ${ }^{2} F_{5 / 2}$ осуществляется в процессе линейной рекомбинации ионизованного иона неодима со свободными электронами, а уровня ${ }^{4} F_{3 / 2}$ - за счет безызлучательных переходов с верхних уровней.

\section{Финансирование работы}

Работа выполнена при финансовой поддержке Российского фонда фундаментальных исследований, грант № 20-08-00018.

\section{Конфликт интересов}

Авторы заявляют, что у них нет конфликта интересов.

\section{Список литературы}

[1] Справочник по лазерам / Под ред. Прохорова А.М. В 2-х томах. Т. І. М.: Сов. радио, 1978. 504 с.

[2] Ikesue A., Kinoshita T., Kamata K., Yoshida K. // J. Am. Ceram. Soc. 1995. V. 78. P. 1033.

[3] Lu J., Prabhu M., Xu J., Ueda K., Yagi H., Yanagitani T., Kaminskii A. // Jpn. J. Appl. Phys. 2000. V. 39. P. 1048.

[4] Bagayev S.N., Osipov V.V., Solomonov V.I., Shitov V.A., Maksimov R.N., Lukyashin K.E., Vatnik S.M., Vedin I.A. // Opt. Mater. 2012. V. 34. P. 1482. doi 10.1016/j.optmat.2012.03.004

[5] Коломийцев А.И., Мейльман М.Л., Володина И.С., Чукичев М.В., Смагин А.Г., Багдасаров Х.С. // Деп. в ВИНИТИ. 5995-82 от 8.12.1982.

[6] Коломийцев А.И., Мейльман М.Л., Володина И.С. Чукичев М.В., Смагин А.Г., Багдасаров Х.С. // Опт. и спектр. 1984. T. 56. № 2. C. 365.

[7] Осипов В.В., Соломонов В.И., Спирина А.В. // Опт. журн. 2011. T. 78. № 6. С. 81; Osipov V.V., Solomonov V.I. Spirina A.V. // J. Opt. Technol. 2011. V. 78. N 6. P. 408.
[8] Гуляева К.Н., Трофимов А.Н., Заморянская М.В. // Опт. и спектр. 2013. Т. 114. № 5. С. 773. doi 10.7868/S0030403413050061; Gulyaeva K.N., Trofimov A.N., Zamoryanskaya M.V. // Opt. Spectrosc. 2013. V. 114. N 5. P. 709. doi 10.1134/S0030400X13050056

[9] Deb K.K., Buser R.G., Paul J. // Appl. Opt. 1981. V. 20. N 7. P. 1203.

[10] Lupei V., Lupei A., Tiseanu C., Georgescu S., Stoicescu C., Nanau P.M. // Phys. Rev. B. 1995. V. 51. N 1. P. 8.

[11] Каминский А.А. Лазерные кристаллы. М.: Наука, 1975. $256 \mathrm{c}$.

[12] Соломонов В.И. // Опт. и спектр. 2003. Т. 95. № 2. С. 266.

[13] Zorenko Y., Zorenko T., Voznyak T., Mandowski A., Xia Qi, Batentschuk M., Fridrich J. // IOP Conf. Series: Materials Science and Engineering. 2010. V. 15 P. 012060. doi 10.1088/1757-899X/15/1/012060

[14] Ларах С., Харди А. // ТИИЭР. 1973. № 7. С. 144. 